\title{
Smart Service Systems in Manufacturing: An Investigation of Theory and Practice
}

\author{
Markus Heuchert \\ University of Muenster - \\ ERCIS \\ heuchert@ercis.de
}

\author{
Yannick Verhoeven \\ University of Muenster - \\ ERCIS \\ y_verh01@uni-muenster.de
}

\author{
Ann-Kristin Cordes \\ University of Muenster - \\ ERCIS \\ cordes@ercis.de
}

\author{
Jörg Becker \\ University of Muenster - \\ ERCIS \\ becker@ercis.de
}

\begin{abstract}
The digitalization has put forward numerous devices dubbed as 'smart'. This development can be observed throughout the entire value chain and across industries with fundamental implications on the co-creation of value. In order to structure this phenomenon, the service science discipline conceptualized so-called smart service systems. This article transfers the theoretical conceptualization into the domain of manufacturing. To assess the state of research on smart services in manufacturing, a structured literature review is performed. As the transfer from a general conceptualization into a concrete domain calls for a more practice-oriented approach, we support our literature study through in-depth interviews with a leading automation technology provider. By interpreting the domain as a smart service system, five barriers to adoption in practice are identified and discussed regarding their implications for research.
\end{abstract}

\section{Introduction}

By the end of 2019, 14.2 billion connected things will be installed according to Gartner [1]. These things are also referred to as 'smart devices', 'smart objects', 'cyber-physical systems', or 'smart products' [2] and take various forms. Ranging from smart watches, over washing machines, to the components of airplanes, one of their main properties is that they can connect digitally to other systems [2]. These smart products provide tremendous opportunities to develop completely new service offerings [3, p. 102].

By capitalizing on the field data of the smart product [2], the service provider and consumer co-create value [4] and thus realize a smart service. As an example, a smart bike lock (smart product) enables me (service consumer) to unlock my bike with my smartphone (another smart product) but also provides value to the producer (service provider) in form of usage data to improve the functionality or identify malfunctions. These settings are conceptualized as smart service systems [2].

Besides end consumers, also industrial applications of smart services are on the advance. Driven by the industry 4.0 paradigm, smart manufacturing can be seen as one major field of action [5], [6]. While computerintegrated manufacturing is by no means a novelty the recent advancements in computation power, device miniaturization [7], as well as in sensing technology [8, p. 352] open up new possibilities. Especially in Germany, former producers of manufacturing machinery shift towards becoming solution providers and envision this as their competitive edge [9].

The importance of the development of smart services for manufacturing is agreed upon by business, politicians, and researchers alike [5, p. 373]. Although the conceptual understanding of smart service systems advances [2], [8], the scientific debate can be described as immature [5]. Moreover, the application in specific domains, such as manufacturing, remains scarce: Practical studies indicate that businesses lack the knowledge required for the successful development and implementation of smart services in manufacturing in spite of high expectations [10, p. 97]. This deficiency from a theoretical and practical view calls for a thorough assessment of the current state in order to answer the research goal of assessing the current state of smart service systems in manufacturing. This assessment serves a dual purpose. On the one hand, it verifies the theoretical conceptualizations of smart service systems by demonstrating their usage in a specific domain. On the other hand, it improves the understanding and peculiarities of the manufacturing domain in the context of (smart) service science

Considering the practical and theoretical standpoint demands a multi-method study. In this regard, we first analyze the extant scientific literature by means of a structured literature review and use this data to compile a list of smart services in manufacturing. In a subsequent review of grey literature in the manufacturing domain, we assess their practical adoption. Further, we 
conducted expert interviews at an international automation technology provider to identify barriers of adoption.

The article is structured as follows. First, we provide the background for smart service systems and the manufacturing domain followed by the presentation of our research approach. In Sections 4 and 5, we present the insights from the scientific and practice-oriented data collection, respectively. Next, the results are discussed and an outlook concludes this article.

\section{Research Background}

\subsection{Smart Services Systems}

Smart service systems extend the notion of a service system which was first mentioned at the 41st Hawaii International Conference of System Sciences (HICSS 2008) [11]. The following journal article by Maglio et al. [12] defined the service system as a "configuration of people, technologies, and other resources that interact with other service systems to create mutual value" [12, p. 395]. Typically, it is differentiated in two parties - the service consumer and service provider [2] - which both benefit by the 'co-creation' of value. A service itself refers to the value-in-use that is co-created in these interactions [4].

The intensified incorporation of digital technology into services has led to the notion of a smart service. However, there is no common view of what actually constitutes the 'smartness'.

Integrating the smart service into the service system yields the smart service system. Lim and Maglio [8] identified 13 definitions for smart service systems. Recurrent in those definitions is some form of learning, intelligence, cognitive ability or automated decision making, with 10 out of 13 definitions incorporating some form of those anthropomorphic features. Those features, which may be summarized as artificial intelligence, are central to the smartness of services and distinguish them from traditional digital or data-driven services [3].

A smart service relies on exploiting data [8, p. 355]. In order to collect and analyze the data necessary for its intelligent behavior, an additional 'thing' is required which is capable of handling these tasks and enables the smart service. Also, this 'thing' gets the prefix 'smart' while the rest is labeled differently: Smart object, smart device, and smart product are three popular varieties. Beverungen et al. [2] use the latter and define smart service systems as "service systems in which smart products are boundary objects that integrate resources and activities of the involved actors for mutual benefit." $[2$, p. 6]
Central to their interpretation is that the smart product as the boundary object acting as an interface between the value co-creators in the smart service system. This view on the smart service system is shared by Wünderlich et al. [13, p. 2f] which argue that a "smart service embodies varying degrees of autonomous and/or intelligent decision-making [via the object]".

Figure 1 shows the conceptualization of a smart service system by Beverungen et al. [2]. By incorporating the four capabilities of smart, connected products by Porter and Heppelmann [7] (monitoring, control, optimization, autonomy), different steps in the smart service can be described. The smart product is used by service consumer and thereby collects data through sensors. This data can be used for monitoring purposes (I.), thereby creating value-in-use for the provider by giving insights into the actual performance of the product and the consumer through using the product itself. As smart products are connected, the data can be used for remote optimization (II.) by the provider. By building on the remote optimization, remote control (III.) then enables the provider to realize physical changes via actuators from afar. Lastly, the smart product can act autonomously (II./IV.) through its actuators. On the one hand, it can directly adapt to account for monitored changes (II.) or it uses the insights from the back-stage analytics (IV.).

While the first type of autonomous acting bases its actions solely on the collected data of the smart product and its data processing capabilities, the second type enables the provider to integrate and exploit the data of the installed base and analyze on remote systems before sending the results back to the smart product.

Smart services can be differentiated into smart interactive services, smart self-services and smart super services [8] each placing emphasis on a different part of

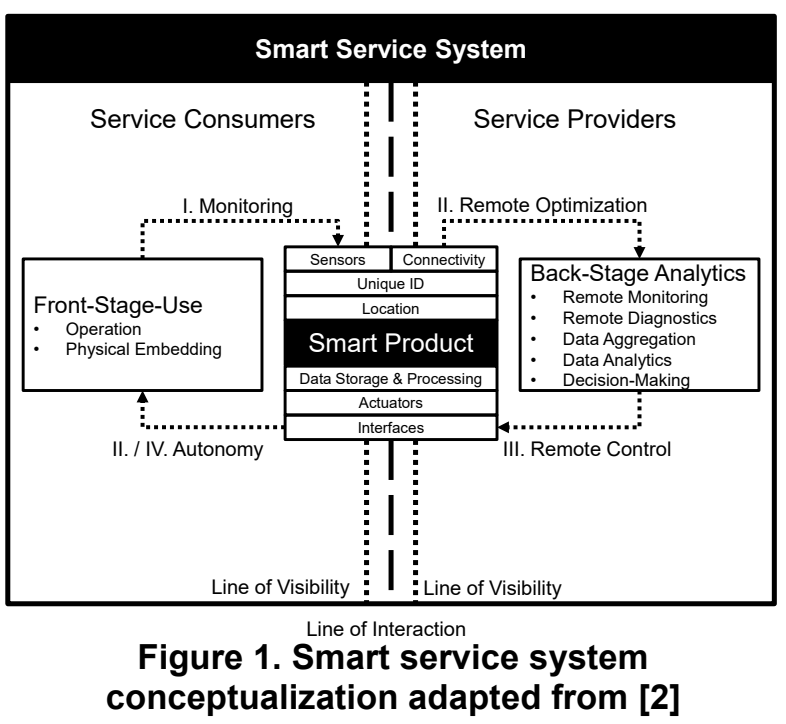


the interaction. Smart services that autonomously provide their service to the consumer are smart selfservices which can be illustrated with the replacement of remote optimization (III.) and remote control (IV.) with autonomy (II.), thus reducing interaction between provider and consumer. Conversely, smart interactive services rely on heavy interaction between the provider and consumer and the smart product takes little part besides its function as a boundary object. Lastly, smart super services focus on the interaction between the smart product and provider (III., IV.) which is the case for performance-based contracts that shift the risk of machine failure to the provider. In this type of scenario, the provider must rely significantly on data generated by the smart product to foresee and avoid breakdowns that lead to costly contractual penalties.

\subsection{Manufacturing in the Industry 4.0}

The fourth industrial revolution or Industry 4.0 redefines the way how manufacturing takes place in the digital world [14]. Equipping physical entities with digital technology denoted as "cyber-physical systems" [15] is one central aspect of this phenomenon. This constitutes a prerequisite for the previously discussed smart products as in manufacturing the different machines in a production line can be seen as the products of a machine manufacturer. The production line belongs to one OEM, i.e. a manufacturer of a final product like an automotive, and is composed of many machines that stem from different machine manufacturers.

Due to the increasing pressure of OEMs to machine manufacturers to incorporate digital technology into machinery in order to realize automation, machine manufacturers must offer sophisticated digital control instruments for their products. As this goes beyond the core capabilities of machine manufacturers - which is engineering - automation technology providers close this gap and add the 'smartness' to the machinery.

Certainly, the previously described system of OEMs, machine manufacturers, and automation technology providers is an abstraction on a high level. Yet, this view enables us to apply the apparatus of smart service systems to this domain by considering smart products (production machinery) and studying their smart services provided and consumed by the actors.

\section{Research Approach}

We chose a multi-method approach to unravel the understanding of smart service systems in manufacturing by combining literature analysis with expert interviews (cf. Figure 2). The former is concerned with scientific as well as grey literature, thereby giving insights about theoretical as well as practical understanding. In-depth interviews enrich the practical understanding further by focusing on challenges in the domain of manufacturing.

The scientific literature review is based on Webster and Watson [16]. Using the taxonomy of Cooper [17] to characterize this review, the focus lies on research outcomes and their potential applications in practice. The goal is to integrate findings from the literature and practice by means of a concept-centric organization. The target audience is characterized by specialized scholars. The coverage is chosen to be representative for the recent years with a neutral perspective.

The search process went as follows. First, the search string was defined which consists of a concept and domain part. Using "smart service" AND (production OR manufacturing OR industry) BETWEEN 2016-2019 ensured the inclusion of both parts and further allows all papers that are concerned with smart services or smart service systems. It ensures domain coverage by including the typical synonyms. The limitation to the recent years ensures the most recent understanding while still relying on backward search to identify seminal papers.

Querying the Springer and ScienceDirect databases yielded 648 and 314 results, respectively, without duplicates. The 962 articles were screened by reading title, abstract, and keywords. This step reduced the amount to 43 . Next, the full-text analysis led to 28 relevant articles e.g. by excluding articles without focus in manufacturing or smart services. The 14 additional articles found through backward search were used for the theoretical foundation, but not in the concept-centric analysis for smart services due to the intended focus on recent articles.

The review of the grey literature had to follow a different approach due to the lack of wide-ranging databases. We chose a company-centric approach where we first identified 23 companies based on the examples in the smart service literature ([7], [18]-[21]). In addition, we examined the German industry as a poster child for mechanical engineering and identified additional 18 companies by identifying those concerned with manufacturing from the top 50 German companies

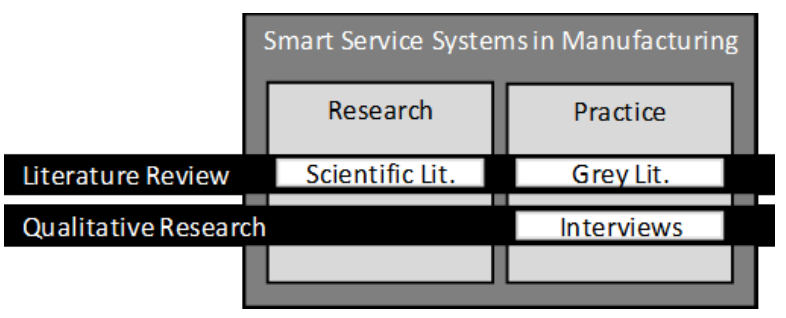

Figure 2. Research Design 
by revenue. We then inspected whitepapers, press releases, brochures, application cases, product and solution catalogs and websites of these 41 companies. As not every company has relevant information publicly available, the final set of companies amounts to 27 .

Both reviews have the smart service as the unit of analysis. Reason for choosing this over smart service system lies in the fact that it is the more established term in the domain of manufacturing while smart service systems are essentially bound to the service science literature. Besides, query-wise, the results on smart service systems are included in the term smart service.

Due to the fact that the articles from the grey literature often have the purpose of being sales material and aim at positioning the company as innovative, their statements must be treated with caution. Thus, we decided to conduct additional expert interviews in the domain to assess the state of adoption. As we looked for a company that is not specialized on one specific branch (e.g. automotive), we considered technology providers in the manufacturing process and found a suitable company which is a leading automation technology provider. The company has a wide array of customers in the manufacturing domain which are typically machine manufacturers. The company yields close to one billion EUR in revenue and operates worldwide. The three interviews lasted between 30 and 50 minutes, were audio recorded and transcribed. The positions of the interviewees were (\#1) product manager IoT, (\#2) head of R\&D and cooperation, and (\#3) hardware developer. The rationale behind choosing these interviewees lies in the expertise in the area of marketing smart service products to the customers (\#1), the knowledge about current research endeavors (\#2), and the implementation-related aspects (\#3), respectively. By taking a semi-structured approach, the interviewees were first introduced into the concept of smart service systems before discussing questions concerning the availability, maturity, challenges, and future development of smart services in manufacturing. The interviews were analyzed via open coding [22].

\section{Smart Service Systems in Manufacturing in the Scientific Literature}

The 28 relevant sources are analyzed in three ways by structuring their contribution, research method and the smart services itself. The latter are further specified into mentions (M), examples (E) and use-cases (U) of smart services. The concept matrix is shown in Table 1.

The contribution of the relevant sources can be distinguished into two main categories: (a) implementation support and (b) scientific discourse on smart services. The former (a) support practitioners by providing guidelines for the development and lifecycle management [9], [10], [23], analyzing the requirements and impacts [9], [24], or developing useable infrastructure [25]. The latter (b) analyze and integrate literature [3], [26], examine the state of the art in practice [19], [27] and literature, and discuss and conceptualize smart services [2], [6].

Method-wise, literature reviews and case studies are commonly used for both types of contributions, but the goal differs. Contributions to the scientific discourse use case studies to learn about the state of the art of smart services in practice [28] while contributions towards the implementation of smart services conduct cases studies to verify their ideas. The latter are often augmented using qualitative research [10], [29] most commonly in the form of expert interviews. Quantitative research [28], [30] is not regularly performed, likely due to the lack of widespread implementation and comparability of smart services across different businesses. A few publications develop smart services in practice, most notably the ongoing research project WerkPriMa [25].

In the analyzed sources, a trend to mention smart services without giving an explanation or example is observable. As an example, Kamp et al. [24], and Paluch [31] mention 12 and 10 smart services respectively, yet do not include what those smart services do, or how. Smart service use cases are even scarcer, with only six out of 28 sources applying or validating their theories in practice. This is in line with the results of Götz et al. [3], who argue that publications broaching the issue of smart services are often written on a general level and do not consider specific smart services. The analysis uncovered a total of 63 mentions (M), 37 examples (E) and 8 use cases (U) of smart services. Challenges that arise when conducting such a recurrence analysis of smart services are the lack of an agreed-upon definition what constitutes a smart service, as well as ambiguous naming of the same services. To allow for a clearer presentation, smart services that are synonymous, closely related or a specification of each other were grouped, and only the most general term (in boldface in Table 1) will be discussed. In line with the building blocks identified in a case study analysis by Mittag et al. [18], monitoring and predictive maintenance are the most prominent examples for smart services in manufacturing-related literature.

Monitoring, which is synonymously used with condition monitoring of assets in a production context, is a common practice in the industry for many years [31] and usually instigated by the production planning department by way of installing sensors [24] which are a foundational part of smart products. Therefore, monitoring has a double role as a necessary enabling activity for other smart services as well as a standalone smart service, as emphasized in the concept matrix. 
Table 1. Smart Services Identified in the Scientific Literature

\begin{tabular}{|c|c|c|c|c|c|c|c|c|c|c|c|c|c|c|c|c|c|c|c|c|c|c|c|c|c|c|c|c|}
\hline & & 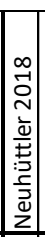 & 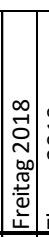 & $\begin{array}{l} \\
\\
\sigma \\
0 \\
0 \\
N \\
00 \\
\frac{0}{0} \\
\frac{D}{N} \\
N\end{array}$ & $\begin{array}{l}1 \\
0 \\
N \\
2 \\
0 \\
0 \\
0 \\
2 \\
0 \\
0 \\
0 \\
0\end{array}$ & 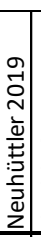 & 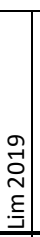 & 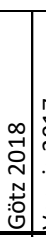 & 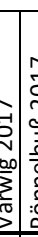 & 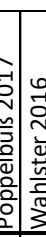 & 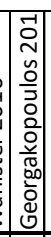 & 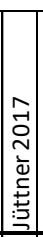 & 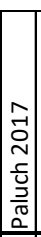 & 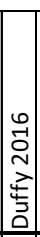 & 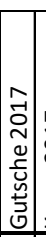 & 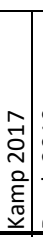 & 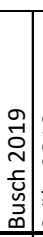 & 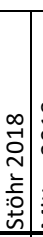 & 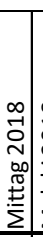 & 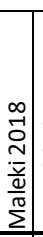 & 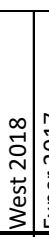 & 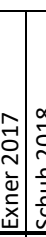 & & & 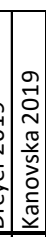 & & 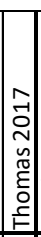 & 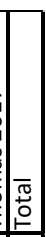 \\
\hline \multirow{8}{*}{ 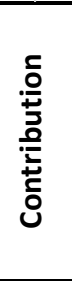 } & Development Guidelines & $\mathrm{x}$ & & & & $\mathrm{x}$ & & & $\bar{x}$ & $\mathrm{x}$ & & $\mathrm{x}$ & & & & & $\mathrm{x}$ & & $\mathrm{x}$ & $\mathrm{x}$ & & \begin{tabular}{c|c}
$x$ \\
$x$
\end{tabular} & $\mathrm{x}$ & & & $\mathrm{x}$ & $x$ & 11 \\
\hline & Lifecycle Management Guidelines & & \begin{tabular}{|l|l}
$x$ \\
\end{tabular} & & & & & & & & & & & & & & $\mathrm{x}$ & & & $\mathrm{x}$ & & $x$ & & & & & $\mathrm{x}$ & 5 \\
\hline & Requirements Analysis & & & $\mathrm{x}$ & & & & & & & & & & & & $\mathrm{x}$ & & $\mathrm{x}$ & & & & & & & & & $\mathrm{x}$ & 4 \\
\hline & Literature Integration & & & & $\mathrm{x}$ & & $\mathrm{x}$ & $\mathrm{x}$ & & & & $\mathrm{x}$ & & & & $\mathrm{x}$ & & $\mathrm{x}$ & & & & & & $\mathrm{x}$ & & & & 7 \\
\hline & Discussion & & & & & & & & $\mathrm{x}$ & $x$ & & & & $\mathrm{x}$ & & & & & & & & & $x$ & & & $x$ & & 5 \\
\hline & State-of-the-Art & & & & & & & $\mathrm{x}$ & $x$ & $x$ & & & & $\mathrm{x}$ & & & & & & & 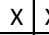 & $\mathrm{x}$ & & $\mathrm{x}$ & $x$ & $\mathrm{x}$ & $\mathrm{x}$ & 10 \\
\hline & Infrastructure Development & & & & & & & & & & $\mathrm{x}$ & & & & & & $\mathrm{x}$ & & & & & & & & & & $\mathrm{x}$ & 3 \\
\hline & Impact Analysis & & & & & & & & & & & & $\mathrm{x}$ & & $\mathrm{x}$ & $\mathrm{x}$ & & & & & . & & & & & & & 3 \\
\hline \multirow{5}{*}{ 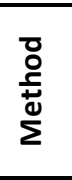 } & Case Study & $\mathrm{x}$ & $\mathrm{x}$ & & & & & & $\gamma$ & $\bar{x}$ & $\mathrm{x}$ & $\mathrm{x}$ & & & & $\mathrm{x}$ & & & $\mathrm{x}$ & $\mathrm{x}$ & $\begin{array}{lll}x & 1 \\
\end{array}$ & \begin{tabular}{l|l}
$x$ & $x$ \\
\end{tabular} & $x \mathrm{x}$ & & $x$ & & & 13 \\
\hline & Literature Review & & & $\mathrm{x}$ & $\mathrm{x}$ & $\mathrm{x}$ & $\mathrm{x}$ & $\mathrm{x}-\mathrm{z}$ & $\mathrm{x}$ & & & & $\mathrm{X}$ & $\mathrm{x}$ & & $\mathrm{x}$ & & $x$ & & & \begin{tabular}{l|l}
$x$ & 1 \\
\end{tabular} & $x$ & $\mathrm{x}$ & \begin{tabular}{l|l}
$x$ & $x$ \\
\end{tabular} & & $\mathrm{x}$ & & 15 \\
\hline & Qualitative Research & & $\mathrm{x}$ & $\mathrm{x}$ & $x$ & $\mathrm{x}$ & & & & $x$ & & & & & & & & & & & & $x$ & & & $\mathrm{x}$ & & & 7 \\
\hline & Quantitative Research & & & & & & & & & & & & & & $\mathrm{x}$ & & & & & & & & & & $\mathrm{x}$ & & & 2 \\
\hline & Design Science Research & & & & & & & & $x$ & $\mathrm{x}$ & $\mathrm{x}$ & & & & & & $\mathrm{x}$ & & & & & $x$ & $\mathrm{x}$ & & & & & 4 \\
\hline \multirow{4}{*}{ 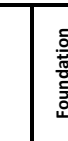 } & Monitoring & & $\mathrm{U}$ & & & & & & & & 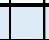 & & & & & & & $E$ & $\bar{E}$ & U & & & & & & & & 4 \\
\hline & Condition Monitoring & $\mathrm{u}$ & & & & & & & & $\mathrm{M}$ & 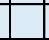 & & & & & & & & & & \begin{tabular}{|l|l}
$E$ & $N$ \\
\end{tabular} & $\mathrm{M}$ & M & & & $\mathrm{M}$ & & 6 \\
\hline & KPI Monitoring \& Assessment & & & & & & & & & & $E$ & & & & & & & & & & & & & & & $\mathrm{E}$ & & 2 \\
\hline & Systems Monitoring & & & & & & & & & & & & $\mathrm{M}$ & & & & & & & & 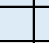 & & & & & $E$ & & 2 \\
\hline \multirow{32}{*}{ 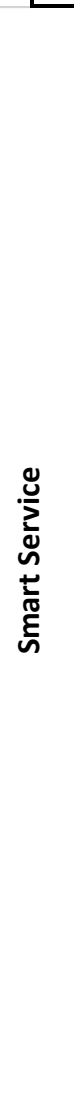 } & Remote Services & & $\mathrm{M}$ & & & & & & & & & $\mathrm{U}$ & $\mathrm{M}$ & & & $\mathrm{M}$ & & & $E$ & & $\mathrm{E}$ & & & & & & $\mathrm{M}$ & 7 \\
\hline & Remote Diagnosis & & & & & & & & 1 & $\mathrm{n}$ & & & & & & & & & & & & & & & $\mathrm{M}$ & & & 2 \\
\hline & Remote Monitoring & & & & & & & & & & & & & & & $\mathrm{M}$ & & & 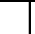 & & & 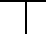 & & & M & & & 2 \\
\hline & Proactive Maintenance & & & & & & & & & $\mathrm{M}$ & & & $\mathrm{M}$ & & & & & & 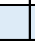 & & & $\mathrm{U}$ & & & & $E$ & $\mathrm{M}$ & 5 \\
\hline & Predictive Maintenance & $M$ & $\mathrm{M}$ & $\mathrm{M}$ & $\mathrm{M}$ & $\mathrm{M}$ & $M$ & & & & & & & & & $\mathrm{M}$ & $E$ & & $\mathrm{U}$ & $u$ & & $E$ & & $E$ & $M$ & $E$ & & 14 \\
\hline & Preventive Maintenance & & & & $\mathrm{M}$ & & & & & $\mathrm{M}$ & & & & & & & $\mathrm{M}$ & & & $\mathrm{M}$ & $\mathrm{E}$ & 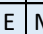 & $\mathrm{M}$ & & $\mathrm{M}$ & & & 8 \\
\hline & Coordinated Maintenance Process & & & & & & & & & & & & & & & & $\mathrm{E}$ & & & & & & & & & & & 1 \\
\hline & Remote Maintenance & & & & & & $\mathrm{M}$ & & & $\mathrm{n}$ & & & $\mathrm{M}$ & & & & & & $E$ & & 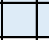 & & & $M$ & $\mathrm{M}$ & & & 6 \\
\hline & Production Optimization & & $\mathrm{M}$ & & & & & & & & & & & & & $\mathrm{M}$ & $\mathrm{M}$ & $E$ & $E$ & & $E$ & & & & & & & 6 \\
\hline & Process Optimization & & & & & & & & & & & & & & & & $\mathrm{E}$ & & & & & & & & & & & 1 \\
\hline & Tool Optimization & & & & & & & & & & & & & & & & $\mathrm{E}$ & & & & $E$ & & & & & & & 2 \\
\hline & Autonomous Production & & & & $\mathrm{M}$ & & & & & & & & $\mathrm{M}$ & & & & & & & & & & & & & & & 2 \\
\hline & Automated Ordering & & & & & & & & & & & & & & & & & & $\mathrm{E}$ & & & & & $E$ & & & & 2 \\
\hline & Spare-Part Pre-Ordering & & & & & & & & & & & & & & & & & $M$ & $M$ & & & & & & & & & 2 \\
\hline & Process Automation & & & & & & & $E$ & & & & & $\mathrm{M}$ & & & & & & & & & & & & & & & 2 \\
\hline & Automatic Updates & & & & & & & & & $\mathrm{M}$ & & & $M$ & & & & & & & & & & & & & & & 2 \\
\hline & Service Support & & & & & & & & & & & & & & & & & & $E$ & & & & & & & & & 1 \\
\hline & Quality Assurance & & & & $\mathrm{M}$ & & & & & & & & $M$ & & & $\mathrm{M}$ & & $\mathrm{E}$ & & & & & & & & & & 4 \\
\hline & Consulting Services & & & & & & & & & & & & $M$ & & & & $\mathrm{M}$ & & & & & & & & & & & 2 \\
\hline & Personell Safety & & & & & & & & & & $E$ & & & & & & & & & & & & & & & $\mathrm{M}$ & & 2 \\
\hline & Asset Management & & & & & & & & & & & $\mathrm{U}$ & & & & & & & & & $\mathrm{M}$ & & & & & & & 2 \\
\hline & Fleet Management & $\mathrm{M}$ & & & & & & & T & E & & & & & & & & & & & & & & & & & & 2 \\
\hline & Specialized Trainings & & & & & & & & & & & & & & & $\mathrm{M}$ & & & & & & & & & & & & 1 \\
\hline & Smart Payment Models & & & & & & & & & & & & & & & $\mathrm{M}$ & & & & & & $\mathrm{E}$ & $E$ & & & & & 3 \\
\hline & Pay-Per-Use & & & & & & & & & & & & & & & $\mathrm{M}$ & & & & & & & $\mathrm{E}$ & & & & & 2 \\
\hline & Pay-Upon-Result & & & & & & & & & & & & & & & $\mathrm{M}$ & & & & & & & $E$ & & & & & 2 \\
\hline & Power-by-the-Hour & & & & $\mathrm{M}$ & & & $E$ & & & & & & & & $\mathrm{M}$ & & & & & & & & & & & & 3 \\
\hline & Machine-as-a-Service & & & & & & & & & & & & $M$ & & & & & & & & & & & & & & & 1 \\
\hline & Performance-Based Contracts & & & & & & & & & & & & & & & & & & & & $\mathrm{M}$ & & $\mathrm{E}$ & & & & & 2 \\
\hline & Plant-Floor-Efficiency & & & & & & & & & & & & & & & $\mathrm{M}$ & & & & & & & & & & & & 1 \\
\hline & Customer Engagement & & & & & & & & & & & & & & & $\mathrm{M}$ & & & & & & & & & & & & 1 \\
\hline & Digital Spare Parts SC & & & & & & & & $E$ & & & & & & & & & & & & & & & & & & & 1 \\
\hline
\end{tabular}

M: Mentioned; E: Example; U: Use Case 
However, the simple monitoring of used production machinery hardly constitutes such a standalone smart service according to our understanding due of the lack of a clear provider and consumer. Still, it is often treated as such. To reach a basic smart service, the data gained through monitoring must be used for value creating activities provided to a consumer, though an argument for a self-service can be made if the smart product uses the data for self-optimization or as the basis for other smart services. Thus, we do not exclude it from the list.

KPI monitoring, that differs from condition monitoring in its assessment of productivity, quality, and safety of processes as opposed to the monitoring of assets, is a smart service that provides real-time personalized KPIs to update management based on realtime computation, visualization, and prediction based on data collected from several connected machines. Quality assurance is a smart service that directly builds on this, extended by automated countermeasures for critical derivations of performance parameters.

In literature, proactive maintenance, predictive maintenance, and preventive maintenance are all named as examples for a smart service, with predictive maintenance being the most prevalent. Following the differentiation by Exner et al. [40], predictive maintenance fits the definition of a smart service if conditions of the machines are considered to predict breakdowns. Preventive maintenance on the other hand, which is performed based on set intervals and therefore triggers independently of the actual condition, does not. Proactive maintenance, an umbrella term for both predictive and preventive maintenance, is hence not necessarily a smart service.

Predictive maintenance as smart services works by collecting sensor data of production machines over an extended time period and deriving correlations between changes in sensor data and machine failures [25]. The smart product may react by triggering the maintenance process should potential breakdown patterns appear during its operation through continuous collection and analysis of sensor data facilitated by embedded sensors, data storage, and processors [9], [29].

Reshuffling responsibilities and financial governance of buyer-supplier relationships by introducing smart products open the door for new payment models [24]. Fundamental for smart payment models is that the risk is transferred to the provider. While traditional, resource-based contracts place the risk on the consumer by selling the resource, performance-based contracts sell the performance of the resource. In business models such as machine-as-aservice, the consumer pays for business outcomes, while the ownership of the machine stays with the provider [20]. The rented smart product gathers and sends data to the provider during its use, enabling further smart service offerings such as "predictive maintenance, quality control, plant-floor efficiency, and customer engagement" [20, p. 9] which optimize the production. In this business model, the provider benefits from the data analysis based on data from a larger installed base and insights into the usage of its machines, potentially by different enterprises. Thus, targeted advice for the operation (tool optimization) and application (process optimization) of the machines, as well as specialized trainings for the consumers' employees that operate the machines and service technicians maintaining the machines [24], can be provided.

Autonomous production is based on truly smart products that can learn and make decisions on their own, thus taking over the role of the service provider. An autonomous production would connect several smart products that communicate their production capabilities and availability between themselves, and autonomously make production planning decisions while continuously optimizing the production process. This possibility is rarely discussed in the literature and no examples or case studies were found. However, according to Lim \& Maglio [8, p. 269], research is standing at the tipping point of true autonomy which "may be viewed as an ideal form of smart self-service systems".

\section{Smart Service Systems in Practice}

\subsection{Grey Literature Review}

In order to delineate the adoption of the previously derived 36 smart services in practice, we analyzed publicly available information of 27 companies. We chose a company-centric approach to be able to identify additional smart services that were not discovered by our scientific literature. While focusing on this small set of mostly German companies admittedly entails its limitations, the fact that the German manufacturing industry is world-leading cannot be denied. Given this maturity, it is likely that it represents thought leadership when it comes to innovations like smart services.

The results in Table 2 show that two particularly popular variates of smart services stand out: monitoring and maintenance. By following the same classification scheme as in Table 1, these classes subsume multiple smart services as a precise allocation to a single smart service from the scientific literature was hard due to vague descriptions in the grey literature. The discussion of these results is continued in chapter 6 .

\subsection{Interview Study}

With the ancillary qualitative research, we inform our study with insights from practice that might be more 
critical than 'whitewashed' releases such as white papers or press releases. Thus, this part focuses on the current challenges in the field, which were then condensed to distinct barriers.

By looking through the lenses of smart service systems, we need to identify service providers and consumers linked by the smart product as a boundary object - which are manufacturing machines in this case. The interviews uncovered two possible avenues for positioning the OEM, machine manufacturer and automation technology provider. On the one hand, the machine manufacturer can be a service provider for the OEM as the service consumer (i). On the other hand, the automation technology provider can be a service provider that enables smart services through its solutions for the machine manufacturer (ii). However, the interviews unveiled that both approaches are obstructed by five barriers to progress which were put forward by the three interviewees \#1-3.

First, an economical barrier exists that is rooted in the fact that the machine manufacturers are highly specialized and have relatively low sales volume (compared to $\mathrm{B} 2 \mathrm{C}$ products). Consequently, their investments are spread between fewer units which results in an excessive price increase for the 'smart' machines. This makes the manufacturer less competitive and hampers the development of smart services, especially when considering (i). In the case of (ii), the lack of efficient billing or business models was mentioned as current models are inconvenient or too complex for the service consumer to be viable for the provider. (\#1, \#2, \#3)

Second, a technological barrier was mentioned. While the foundational capability to store e.g. sensor data on the product or in the cloud for backstage analytics was not seen as an issue, the lack of standardization and IT infrastructure was mentioned as one obstacle.

Table 2. Smart Services Identified in the Grey Literature

\begin{tabular}{|lr|}
\hline Smart Service & Count \\
\hline *-Monitoring & 14 \\
\hline *-Maintenance & 11 \\
\hline Fleet Management & 3 \\
\hline Smart Grid ${ }^{+}$ & 3 \\
\hline Automated Ordering & 2 \\
\hline Autonomous Production & 1 \\
\hline Remote Monitoring & 1 \\
\hline Pay-Per-Use & 1 \\
\hline Personnel Safety & 1 \\
\hline Process Optimization & 1 \\
\hline Quality Assurance & 1 \\
\hline Remote Diagnosis & 1 \\
\hline Remote Services & 1 \\
\hline Smart Payment Models & 1 \\
\hline [Remaining 16 Smart Services] & 0 \\
\hline
\end{tabular}

indicate new smart services
As the OEM has multiple machines from multiple machine manufacturers on the plant floor, a common platform is desirable, yet absent. Further, the machines produce a high amount of raw data. Aggregation entails the risk of losing critical information and the data preprocessing that might be necessary for analytics again depends on the type of machine itself. (\#1, \#2)

Third, a lack of know-how was identified as profound mechanical and data analytical skills are required at a service provider for crafting smart services. As explained, machine manufacturers are typically SMEs that are specialized in engineering. Besides, the automation technology provider is often responsible for the digital control of the machinery. However, the automation technology provider does not know the machine as good as its engineers. While it was agreed that theoretically, the automation technology provider is able to acquire the necessary know-how and take the role of the service provider, the economic barrier and the following two barriers dampen these initiatives. (\#2, \#3)

Fourth, the interviewees stated a lack of trust or the fear of losing know-how. As explained before, the lack of know-how calls for external support. However, the necessary sharing of data to the service provider or a provider of cloud infrastructure poses the risk of exposing critical technical details. This is amplified by the small niches that machine manufacturers are operating in: With a few direct competitors comes the accumulation of distinctive know-how. (\#1, \#2, \#3)

Fifth, the experts stated that the ownership of data produced in a manufacturing context is not clear but handled on a case-by-case basis. This hampers the development of smart services as potential service providers are not sure whether they are allowed to use the data of the OEM's production collected by the machine manufacturer's product which may be recorded by the automation technology provider's solutions. This legal issue was pointed out as a major constraint that demands guidance by the authorities. $(\# 2, \# 3)$

\section{Discussion}

Blending the results from the scientific and grey literature review along with the results with the qualitative research draws a vivid picture of smart service systems in manufacturing: The literature reviews identified the different instances of smart services and underlined that different forms of monitoring and maintenance enjoy the most popularity from a scientific as well as a practical perspective.

While the role of the OEM, machine manufacturer and automation technology provider as the service provider and consumer can change, the production machine persists as the smart product in this context. 
When considering the classification of [8], smart super services and smart self-services (focusing on the interaction of the product with the provider and consumer, respectively) currently seem to be more prevalent in manufacturing than smart interactive services (focusing on the interaction between provider and consumer). A reason for this can be that a production machine is a product with a clear function in the OEM's production line, as opposed to smart products in a $\mathrm{B} 2 \mathrm{C}$ context which may have one function, but can also offer value in other areas (e.g. a smart watch offering health tips). Thus, in a production context, the services are focused on the function of the machine and hence involve the machine in the service. Interactive services may become more relevant in the future, when the providers are able to create service offerings beyond the single machine. For instance, an automation technology provider may offer recommendations to the machine manufacturer. In the interviews, the substitution of sensors in the machine because of similar data patterns was named as a possibility.

Smart services existing in the literature besides monitoring or maintenance currently show less evidence of practical use. The listing of the Smart Grid in Table 2 without reflection in the scientific literature can be explained with it being a research field on its own and manufacturing only being one application domain. Due our search query for the scientific literature, these were not included in the analysis. The absence of the remaining 16 services is not to be interpreted as their nonexistence in practice, but rather as an indication for a different label than smart service from a practitioner's view or due to the limited data set. However, the novelty of the field may require more time for the dissemination of scientific knowledge in practice, yet the barriers identified by the expert interviews indicate that there might be a structural problem as well.

While value co-creation stands in the center of every smart service, the question after the concrete beneficiaries is often left unanswered. Certainly, all scientific works on smart services in manufacturing articulate a clear value proposition, e.g. reducing downtimes by predicting maintenance actions, yet they seldom elaborate on the service consumers and providers in practice explicitly. As emphasized in the interviews, the different actors in the manufacturing domain pursue different goals. Smart service systems offer a promising view to include these aspects in the analysis and development of smart service systems.

Implications for research can be drawn from the five identified barriers. Regarding the economic barrier, a need for more consideration of the 'meso' level of smart service systems in manufacturing can be concluded to include the different goals of the actors in the domain. This means that neither a 'macro' level with a focus on the actors on industry level (as taken in this paper) nor a 'micro' level (focusing strongly on the technical aspects as typically done in the literature) is deemed sufficient. A 'meso' level would realize a better understanding of business models for smart service systems in manufacturing while maintaining the connection to the technical implementation which is needed for adoption in practice. The identified smart service literature focusing on requirements analysis may offer the possibility for integrating this matter.

The technological barrier calls for more research on data preprocessing of raw data from manufacturing machines. Further, a reference architecture for data integration among different machines is needed. The Reference Architecture Model Industry 4.0 [41] is one step in this direction. The research streams on infrastructure development and development guideline" offer an interesting starting point is this regard.

On the plant floor, the OEM acts as the resource integrator in the sense of service science since the production of the final product utilizes various materials and machines. While not having the detailed view on the machinery compared to the automation technology provider or the machine manufacturer, it lies in the OEM's interest to optimize the own production which typically is composed of different machines from different manufacturers. Adding a layer of abstraction so that the OEM is able to work with prepared data from the service providers (related to the case (i) or (ii)) may result in new kinds of smart services. These would deliver value to the OEM as a service consumer in the form of data easy-to-use in synthesizing analyses of the manufacturing line.

The lack of know-how as the third barrier results in an indirect call for action direct to research. As the skill shortage is rooted in the current proliferation of the digitalization in all spheres, this requires more incentives from the companies so that more experts work in this particular field. However, research may disseminate the knowledge necessary for the development of smart services. In this regard, the 11 identified papers (see Table 1) provide fertile ground for further research.

The lack of trust, encapsulated in barrier four, must be analyzed by means of behavioristic research. If the causes of this phenomenon are understood better, adequate countermeasures may be identified. Smart service systems research alone will not be able to address this challenge. Still, it can be a tool for communicating the intentions of the different actors and describing value creation.

As the former barrier, the blurry regulations on the ownership of data as the fifth barrier can neither be solved by smart service systems research alone. Instead, it calls for an investigation from a legal perspective and 
is seen as a prerequisite for the broad adoption of smart services in practice.

Every work comes with its limitations. The scientific literature review was necessarily restricted to recently published articles and due to the limitation to two databases, not every article was included. Nevertheless, querying two very popular databases yields a comprehensive view of the scientific work in the field. Connected to this, the grey literature review must also be understood as an indication with no claim of being exhaustive as well as the deduction of barriers being limited to the three interviews. As stated before, the focus on the German manufacturing industry also entails limitations. However, given the world-leading position, its maturity thus gives an edge over other markets for comparing it to the advances in science. Lastly, conducting the interviews with employees of a single company shrinks the generalizability of statements. Still, our automation technology provider as a multinational corporation touches a wide array of markets in the manufacturing domain and is consequently seen as a suitable informant for this study.

\section{Conclusion}

This paper investigated smart service systems in the domain of manufacturing. By means of a multi-method approach, a comprehensive literature analysis was combined with in-depth expert interviews. By compiling the different smart services from the literature, an overview of the different research streams in the domain is given. A complementary analysis of grey literature confirmed the focus on the different variants of 'monitoring' and 'maintenance' smart services. In order to enrich the understanding of current challenges in practice, the in-depth interviews with a leading automation technology provider were conducted. By interpreting the manufacturing domain as a smart service system, five barriers of adoption were identified and further discussed regarding the implications for research. This view has proven to be a powerful tool to derive structural problems in the domain. Most notably, the need for a profound analysis of the roles of the service providers and consumers became apparent. In this regard, a 'meso' level of analysis that reflects the aims and intentions of the different actors in the domain is called for. This is necessary because the current contributions often focus on the 'micro' level, i.e. the usefulness of a smart service in its production environment, but abstracts from the intentions of the involved actors (i.e. organizations).

By moving away from the popular field of smart services in B2C markets, this work has investigated in another promising $\mathrm{B} 2 \mathrm{~B}$ domain for (smart) service research. As the five identified barriers to adoption show, the proliferation of smart services is not limited by technological progress, but rather bound by the composition of the market and its actors. In this regard, smart service systems are seen as a promising avenue of research to define smart services with value propositions beneficial and viable for providers and consumers alike.

\section{Acknowledgment}

The authors thank Mr. Johannes Beckhoff for enabling the access to the practical expertise used in this research.

\section{References}

[1] Gartner, "Gartner Identifies Top 10 Strategic IoT Technologies and Trends," 2018.

[2]D. Beverungen, O. Müller, M. Matzner, J. Mendling, and J. Vom Brocke, "Conceptualizing smart service systems," Electron. Mark., Nov. 2017, pp. 1-12.

[3]C. Götz, S. Hohler, and C. Benz, "Towards Managing Smart Service Innovation: A Literature Review," vol. 331. Springer, Cham, 2018.

[4] S. L. Vargo and R. F. Lusch, "Why 'service'?," J. Acad. Mark. Sci., vol. 36, no. 1, Mar. 2008, pp. 25-38.

[5]U. Jüttner, K. Windler, A. Schäfer, and A. Zimmermann, "Design von Smart Services - Eine explorative Studie im Business-to-Business-Sektor," in Dienstleistungen 4.0, Wiesbaden: Springer Fachmedien Wiesbaden, 2017, pp. 335-361.

[6]W. Wahlster and D. Beste, "Industrie 4.0 und SmartService-Welt," HERMES AWARD - Internationaler Technologiepreis der HANNOVER MESSE. Essentials. Springer Vieweg, Wiesbaden, 2016, pp. 1-8.

[7]M. E. Porter and J. E. Heppelmann, "How Smart, Connected Products Are Transforming Competition," Harvard Business Review, vol. 92, Nov. 2014, pp. 64-88.

[8]C. Lim and P. P. Maglio, "Clarifying the Concept of Smart Service System," in Handbook of Service Science, Volume II, S. Y. Maglio P., Kieliszewski C., Spohrer J., Lyons K., Patrício L., Ed. Springer, Cham, 2019, pp. 349376.

[9] W. Zhang, J. Neuhüttler, M. Chen, and W. Ganz, "Smart services conditions and preferences - an analysis of chinese and german manufacturing markets," in Advances in Intelligent Systems and Computing, vol. 787, 2019, pp. 183194.

[10] M. Freitag and S. Wiesner, "Smart service lifecycle management: A framework and use case," in IFIP Advances in Information and Communication Technology, vol. 536, 2018, pp. 97-104.

[11] D. Beverungen, M. Matzner, and C. Janiesch, "Information systems for smart services," Inf. Syst. E-bus. Manag., vol. 15, no. 4, 2017, pp. 781-787.

[12] P. P. Maglio, S. L. Vargo, N. Caswell, and J. Spohrer, "The service system is the basic abstraction of service 
science," Inf. Syst. E-bus. Manag., vol. 7, no. 4, Sep. 2009 , pp. 395-406.

[13] N. V. Wuenderlich et al., "'Futurizing' smart service: implications for service researchers and managers," J. Serv. Mark., vol. 29, no. 6-7, Sep. 2015, pp. 442-447.

[14] H. Lasi, P. Fettke, H.-G. Kemper, T. Feld, and M. Hoffmann, "Industry 4.0," Bus. Inf. Syst. Eng., vol. 6, no. 4 , Aug. 2014, pp. 239-242.

[15] P. Leitão, A. W. Colombo, and S. Karnouskos, "Industrial automation based on cyber-physical systems technologies: Prototype implementations and challenges," Comput. Ind., vol. 81, Sep. 2016, pp. 11-25.

[16] J. Webster and R. T. Watson, "Analyzing the Past to Prepare for the Future : Writing a Literature Review," MIS Q., vol. 26, no. 2, 2002.

[17] H. M. Cooper, "Organizing knowledge syntheses: A taxonomy of literature reviews," Knowl. Soc., 1988.

[18] T. Mittag, M. Rabe, T. Gradert, A. Kühn, and R. Dumitrescu, "Building blocks for planning and implementation of smart services based on existing products," in Procedia CIRP, 2018, vol. 73, pp. 102-107.

[19] S. West, P. Gaiardelli, and M. Rapaccini, "Exploring technology-driven service innovation in manufacturing firms through the lens of Service Dominant logic," IFACPapersOnLine, vol. 51, no. 11, Jan. 2018, pp. 1317-1322.

[20] J. Macaulay, K. O. Connell, and K. Delaney, "The Digital Manufacturer - Resolving the Service Dilemma," Cisco, Nov. 2015, pp. 1-20.

[21] M. E. Porter and J. E. Heppelmann, "How Smart, Connected Products Are Transforming Companies," Harvard Business Review, Oct. 2015.

[22] A. Strauss and J. Corbin, "Basics of Qualitative Research," 2nd ed. Sage, 1998.

[23] J. Neuhüttler, I. C. Woyke, and W. Ganz, “Applying value proposition design for developing smart service business models in manufacturing firms," in Adv. in Int. Sys. and Comp., vol. 601, 2018, pp. 103-114.

[24] B. Kamp, A. Ochoa, and J. Diaz, "Smart servitization within the context of industrial user-supplier relationships: contingencies according to a machine tool manufacturer," Int. J. Interact. Des. Manuf., vol. 11, no. 3, Aug. 2017, pp. 651-663.

[25] M. Busch, J. de Lange, C. Kelzenberg, and G. Schuh, "Achieving Process Efficiency and Stability in Serial Production Through an Innovative Service System Based on Predictive Maintenance," in Advances in Production Research, Cham: Springer International Publishing, 2019, pp. 657-666.

[26] S. Dreyer, D. Olivotti, B. Lebek, and M. H. Breitner, "Focusing the customer through smart services: a literature review," Electron. Mark., vol. 29, no. 1, Mar. 2019, pp. 5578.

[27] A. Diez-Olivan, J. Del Ser, D. Galar, and B. Sierra, "Data fusion and machine learning for industrial prognosis: Trends and perspectives towards Industry 4.0," Inf. Fusion, vol. 50, Oct. 2019, pp. 92-111.
[28] L. Kanovska and E. Tomaskova, "Data gained from smart services in SMEs - Pilot study," in Advances in Intelligent Systems and Computing, vol. 859, 2019, pp. 183200.

[29] J. Neuhüttler, I. Woyke, W. Ganz, and D. Spath, “An Approach for a Quality-Based Test of Industrial Smart Service Concepts," in Advances in Intelligent Systems and Computing, vol. 787, 2019, pp. 171-182.

[30] K. Gutsche and J. Griffith, "Automating motivation: A workplace analysis of service technicians and the motivational impact of automated assistance," in $L N C S$, vol. 10371, 2017, pp. 101-108.

[31] S. Paluch, "Smart Services - Analyse von strategischen und operativen Auswirkungen," in Dienstleistungen 4.0, Wiesbaden: Springer Fachmedien Wiesbaden, 2017, pp. 161-182.

[32] V. G. Duffy, "Modern human-robot interaction in smart services and value co-creation," in $L N C S$, vol. 9745, 2016, pp. $399-408$.

[33] A. Varwig, F. Kammler, and O. Thomas, "Geschäftsmodellevolution im Technischen Kundendienst des Maschinen- und Anlangenbaus durch additive Fertigung -- Ersatzteilbereitstellung als smart Service," in Additive Manufacturing Quantifiziert: Visionäre Anwendungen und Stand der Technik, Berlin, Heidelberg: Springer Berlin Heidelberg, 2017, pp. 133-143.

[34] D. Georgakopoulos and P. P. Jayaraman, "Internet of things: from internet scale sensing to smart services," Computing, vol. 98, no. 10, Oct. 2016, pp. 1041-1058.

[35] C. Stöhr, M. Janssen, J. Niemann, and B. Reich, "Smart Services," Procedia - Soc. Behav. Sci., vol. 238, Jan. 2018, pp. 192-198

[36] E. Maleki, F. Belkadi, and A. Bernard, "Industrial Product-Service System modelling base on Systems Engineering: Application of sensor integration to support smart services," IFAC-PapersOnLine, vol. 51, no. 11, Jan. 2018, pp. 1586-1591.

[37] G. Schuh, P. Jussen, and T. Harland, "The Digital Shadow of Services: A Reference Model for Comprehensive Data Collection in MRO Services of Machine Manufacturers," in Procedia CIRP, vol. 73, 2018, pp. 271277.

[38] T. Grubic and I. Jennions, "Do outcome-based contracts exist? The investigation of power-by-the-hour and similar result-oriented cases," Int. J. Prod. Econ., vol. 206, Dec. 2018, pp. 209-219.

[39] O. Thomas, F. Kammler, D. Özcan, and M. Fellmann, "Digitale Plattformstrategien als Treiber der Dienstleistungsflexibilisierung im Maschinen- und Anlagenbau," in Dienstleistungen 4.0, Wiesbaden: Springer Fachmedien Wiesbaden, 2017, pp. 481-494.

[40] K. Exner, C. Schnürmacher, S. Adolphy, and R. Stark, "Proactive Maintenance as Success Factor for Use-Oriented Product-Service Systems," in Procedia CIRP, vol. 64, 2017, pp. 330-335.

[41] DIN SPEC, “91345: Referenzarchitekturmodell Industrie 4.0 (RAMI4. 0)," Dtsch. Inst. für Normung eV, 2016. 